\title{
PENGEMBANGAN DESAIN SEPEDA ANAK USIA 7-12 TAHUN MENGGUNAKAN METODE RAPID ETHNOGRAPHY DAN SCAMPER
}

\author{
Marcellino Aditya Mahendra ${ }^{1}$, Rini Dharmastiti ${ }^{2}$ \\ 1. Prodi Desain Produk, Fakultas Arsitektur dan Desain, Universitas Kristen Duta Wacana \\ Jl. dr. Wahidin Sudirohusodo no. 5-25, Yogyakarta \\ 2. Prodi Teknik Industri, Departemen Teknik Mesin dan Industri, Universitas Gadjah Mada \\ Senolowo, Sinduadi, Mlati, Sleman \\ Email: marcellinoam@staff.ukdw.ac.id, rini@ugm.ac.id
}

\begin{abstract}
Abstrak
Pertumbuhan badan anak yang pesat ini tidak diimbangi dengan adanya desain sepeda anak yang dapat bertumbuh, juga menyesuaikan pertumbuhan tubuh anak. Untuk memenuhi kebutuhan kenyamanan anak dalam bersepeda, maka diperlukan beberapa sepeda yang sesuai dengan antropometri tubuh anak. Dengan adanya desain sepeda yang memiliki masa pakai yang lebih lama dari sepeda anak pada umumnya, maka sepeda anak yang nantinya akan di desain akan memiliki konsep sustainable design. Menurut Clark et al. (2009), sustainable design merupakan konsep desain yang mengintegrasikan 3 jenis elemen (people, profit, planet) dan tidak hanya sekedar konsep ramah lingkungan. Pengembangan produk dengan konsep sustainable tidak hanya dilakukan dengan upaya rekayasa pada material yang memiliki sifat bio-degradable, namun bisa juga dilakukan dengan memperpanjang masa pakai produk. Responden yang dibidik dalam perancangan ini adalah anak berusia 7 sampai 12 beserta orang tuanya, karena dalam range usia ini anak juga mengalami pertumbuhan badan yang pesat. Tidak hanya anak usia 7-12 tahun sebagai user primer, namun kepentingan serta kebutuhan orang tua sebagai user sekunder juga diperhatikan. Hal ini dikarenakan orang tua juga turut berperan serta dalam pemilihan dan pembelian sepeda yang akan digunakan oleh anaknya.
\end{abstract}

Kata kunci: perancangan produk, rapid ethnography, sustainable product, SCAMPER, sepeda anak.

\begin{abstract}
Title: Design Development of Bike for Kids (7-12 y.o) using Rapid Ethnography and SCAMPER Method

Children by nature growth relatively fast. Their body expand in a short time that demand many things that they wear or use to meet their body accordingly. This to include also the need for their bicycle. In order to fulfill the needs of children's comfort in cycling, some bicycles which are suitable with anthropometry of children's body are required. With the existence of bicycle's design which has longer durability than children's bicycles in general, hence the children's bicycle which will be designed would have sustainable design concept. Clark et al. (2009) states that sustainable design is a design concept which integrates 3 kinds of elements (people, profit, planet) and not merely an environmental-friendly concept. Developing a product with sustainable concept is not only done with a manipulation on materials which are bio-degradable, but also could be done with extending the lifespan of the product. Respondents which are targeted on this planning are children aged from 7 until 12 with their parents, since the children on this age range experience rapid growth. Not only the interests of the children aged from 7-12 as primer users which are concerned, but also their parents as secondary users. This matter is resulted from how the parents also play a role in choosing and buying the bicycle which will be used by their children.
\end{abstract}

Keywords: product design, rapid ethnography, sustainable product, SCAMPER, kids bike. 


\section{Pendahuluan}

Pertumbuhan badan anak yang pesat ini tidak diimbangi dengan adanya desain sepeda anak yang dapat bertumbuh, juga menyesuaikan pertumbuhan tubuh anak. Untuk memenuhi kebutuhan kenyamanan anak dalam bersepeda, maka diperlukan beberapa sepeda yang sesuai dengan anthropometri tubuh anak. Dengan adanya desain sepeda yang memiliki masa pakai yang lebih lama dari sepeda anak pada umumnya, maka sepeda anak yang nantinya akan di desain akan memiliki konsep sustainable design. Menurut Clark et al. (2009), sustainable design merupakan konsep desain yang mengintegrasikan 3 jenis elemen (people, profit, planet) dan tidak hanya sekedar konsep ramah lingkungan. Pengembangan produk dengan konsep sustainable tidak hanya dilakukan dengan upaya rekayasa pada material yang memiliki sifat bio-degradable, namun bisa juga dilakukan dengan memperpanjang masa pakai produk. Responden yang dibidik dalam perancangan ini adalah anak berusia 7 sampai 12 tahun beserta orang tuanya, karena dalam range usia ini anak juga mengalami pertumbuhan badan yang pesat. Tidak hanya anak usia 7-12 tahun sebagai user primer, namun kepentingan serta kebutuhan orang tua sebagai user sekunder juga diperhatikan. Hal ini dikarenakan orang tua juga turut berperan serta dalam pemilihan dan pembelian sepeda yang akan digunakan oleh anaknya.

\section{Metode}

\section{Rapid Ethnography}

Rapid ethnography merupakan salah satu jenis metode pendekatan etnografi. Salah satu hambatan dalam pengembangan desain produk berbasis industri adalah waktu. Peneliti dan desainer yang berperan dalam pengembangan desain mengenal istilah rapid ethnography. Metode ini membantu desainer dan peneliti untuk mendapatkan customer need dari bakal pengguna dengan cepat. Kedalaman data yang diperoleh dapat dianggap mendekati kedalaman data dari metode etnografi konvensional, namun dapat dilakukan dengan waktu yang singkat. Menurut Rodgers dan Anusas (2008) dalam pengembangan produk menggunakan pendekatan etnografi, biasanya desainer membutuhkan jawaban dalam waktu yang singkat, sedangkan biasanya penelitian etnografi membutuhkan waktu berbulan-bulan, bahkan bertahun-tahun.

Ada sebuah varian dari pendekatan etnografi secara konvensional, yaitu rapid etnography. Teknik ini merupakan cara yang efektif dan efisien untuk mencapai hasil yang relatif dalam untuk mengetri kebiasaan orang yang diteliti. Desainer yang menggunakan teknik ini harus bisa mendefinisikan tujuan serta langkah-langkah yang akan dilakukan dalam melakukan penelitian. Teknik ini memiliki 3 hal yang harus dilakukan, yaitu:

1. Menyempitkan tujuan dari penelitian sebelum melakukan pengamatan/observasi di lapangan.

2. Menggunakan berbagai teknik observasi interaktif untuk menambah kemungkinan beragamnya hasil dan mendapatkan hasil yang relevan sesuai perilaku pengguna.

3. Menggunakan metode iteratif dalam mengolah hasil data pengamatan /observasi. 


\section{SCAMPER}

Dalam menghasilkan produk yang inovatif, desainer dituntut untuk bisa menghasilkan alternatif-alternatif konsep. Salah satu yang dapat digunakan adalah metode SCAMPER. Menurut Serrat (2009), metode SCAMPER adalah salah satu metode brainstorming yang menggunakan sekumpulan pertanyaan yang ditujukan untuk menyelesaikan sebuah masalah atau menghasilkan sebuah solusi. Metode ini juga bisa digunakan untuk mengubah ide yang sudah ada menjadi sesuatu yang baru dan berbeda. Metode SCAMPER merupakan sebuah akronim yang terdiri dari substitute, combine, adapt, magnify/modify, put to toher uses, eliminate, rearrange/reverse.

\section{Obyek Perancangan}

Obyek perancangan sepeda anak ini merupakan pengembangan fungsi adjustable pada sepeda anak. Beberapa hal yang diperhatikan dalam mengembangkan fungsi adjustable adalah tinggi sadel, tinggi stang dan panjang kerangka sepeda. Sepeda anak yang dapat memiliki fungsi adjustable memiliki jangka umur pemakaian produk yang lebih lama jika dibandingkan dengan sepeda anak yang ada di pasaran. Hal ini dikarenakan desain sepeda anak yang adjustable akan dapat disesuaikan dengan perkembangan tubuh anak. Untuk mendapatkan customer needs dari pengguna primer (anak usia 7-12 tahun) dan sekunder (orang tua) maka digunakan pendekatan rapid ethnography dengan jumlah responden yaitu 1 anak pada setiap umur mulai dari usia 6 sampai 12 tahun beserta orang tuanya masingmasing. Dalam penelitian ini menggunakan tidak hanya satu responden, dengan tujuan untuk memperkaya customer need sehingga dapat memperbanyak alternatif desain yang dapat dihasilkan dengan dilengkapi 4 teknik etnografi secara spesifik yaitu: netnography, non-participatory, observation, contextual in-depth interview, photography and videography.

\section{Identifikasi Kebutuhan User dengan Etnografi}

Tahap ini diawali dengan pengumpulan data dari sumber internet (netnography), untuk menemukan gambaran besar tentang masalah yang dihadapi user saat belajar mengendarai sepeda/bermain sepeda. Data ini nantinya akan digunakan untuk bekal peneliti sebelum melakukan observasi. Tahap selanjutnya adalah dengan melakukan observasi (nonparticipatory observation) pada saat anak-anak bermain sepeda. Tahap kedua ini didukung pula dengan pengambilan dokumentasi berupa foto dan video (photography and videography). Pengamatan perilaku saat bersepeda dilakukan pada 1 anak pada setiap range umur (7-12 tahun). Tahap selanjutnya adalah dengan melakukan wawancara secara mendalam (Contextual in-depth interview) kepada orang tua masingmasing anak yang telah diamati di tahap sebelumnya. Pada tahap interview ini, dilakukan juga proses perekaman interview sebagai data penunjang apabila diperlukan.

\section{Menentukan Spesifikasi Produk}

Berdasarkan hasil observasi dan wawancara, kemudian disusun daftar keluhan dan saran dari user untuk diterjemahkan menjadi tabel yang berisi atribut spesifikasi produk, yang nantinya akan digunakan sebagai pedoman tahap selanjutnya. 


\section{Benchmarking Existing Product}

Sebelum menghasilkan alternatifalternatif desain, dilakukan benchmarking pada produk-produk yang memiliki atribut spesifikasi produk yang mirip dengan kebutuhan user.

\section{Menghasilkan Alternatif-Alternatif Desain \\ Dalam tahap ini desainer akan menghasilkan beberapa alternatif desain sepeda berdasarkan tabel spesifikasi produk. Metode kreatif yang akan digunakan adalah SCAMPER. Dari metode SCAMPER (substitution, combine, adapt, modify, put to other use, elimination, reverse) akan dipilih 2-3 pendekatan dalam SCAMPER sebagai pedoman peneliti menghasilkan alternatif desain. Alternatif-alternatif desain dipresentasikan dalam bentuk thumbnail sketch dengan menggunakan hasil benchmarking existing product.}

\section{Memilih Freeze Design Berdasarkan Pilihan User}

Dalam tahap ini dilakukan penilaian alternatif desain oleh 6 anak pada setiap jangka umur (umur 7-12 tahun) beserta orang tuanya. Variabel penilaian yang digunakan adalah bentuk, style dan keamanan. Skala yang digunakan untuk setiap variabel adalah skala Likert dengan bobot sangat puas (5), puas (4), cukup puas (3), kurang puas (2) dan sangat tidak puas (1). Sketsa dengan nilai tertinggi akan dipilih untuk diwujudkan dalam digital modeling.

\section{Pembuatan Hasil Akhir Desain}

Proses pembuatan hasil akhir desain melalui bentuk 3D menggunakan aplikasi Autodesk 3Ds Max sesuai dengan desain yang terpilih pada tahap sebelumnya. Hasil akhir desain berupa gambar rendering $3 D$ sepeda akan diberikan kepada user, sehingga user dapat memberikan feedback yang akan dicantumkan dalam bagian saran. Metode yang digunakan adalah wawancara kepada user.

\section{Hasil dan Pembahasan}

\section{Identifikasi Kebutuhan User}

Identifikasi kebutuhan user dilakukan menggunakan rapid ethnography yang terdiri dari 4 tahap, yaitu netnography, non-participatory observation, contextual in-depth interview dan photo/ video. Tahap observation dilakukan secara acak di Grha Sabha Pramana pada sore hari. Konfirmasi ulang diperlukan pada tahap observation untuk mengetahui apakah range umur anak yang diamati antara 7-12 tahun, bila sesuai maka akan dilanjutkan ke tahap contextual in-depth interview. Dari hasil wawancara didapatkan opini dan keluhan baik dari anak dan orang dewasa yang mendampingi. Responden juga diminta untuk mengomentari hasil observasi yang sudah dilakukan. Data yang dihasilkan dari proses pengamatan dan wawancara dirasa kurang mendalam, karena kurangnya data opini dari orang tua dari responden. Sehingga, dilakukan wawancara kepada beberapa orang tua dari anak berumur 7-12 tahun yang memiliki sepeda, tentang hasil penelusuran netnography dan nonparticipatory observation. Tabel 1 berikut merupakan atribut spesifikasi produk. 
Tabel 1. Atribut spesifikasi produk

\begin{tabular}{|c|c|}
\hline Atribut & $\begin{array}{c}\text { Design } \\
\text { Requirement }\end{array}$ \\
\hline \multirow[t]{3}{*}{ Sustainability } & $\begin{array}{l}\text { Dapat digunakan } \\
\text { oleh anak umur 7-12 } \\
\text { tahun. }\end{array}$ \\
\hline & $\begin{array}{l}\text { Dapat digunakan } \\
\text { oleh anak laki-laki } \\
\text { dan perempuan. }\end{array}$ \\
\hline & $\begin{array}{l}\text { Adanya sistem yang } \\
\text { mengakomodir } \\
\text { mode balance bike } \\
\text { untuk memudahkan } \\
\text { proses belajar } \\
\text { bersepeda. }\end{array}$ \\
\hline \multirow[t]{3}{*}{ Kenyamanan } & $\begin{array}{lr}\text { Adanya fender } & \text { untuk } \\
\text { (slebor) } & \text { user } \\
\text { melindungi } & \text { air. } \\
\text { dari percikan air. }\end{array}$ \\
\hline & $\begin{array}{ll}\text { Sparepart } & \text { dapat } \\
\text { dengan } & \text { mudah } \\
\text { dibeli. } & \\
\end{array}$ \\
\hline & $\begin{array}{l}\text { Bagian-bagian pada } \\
\text { sepeda dapat } \\
\text { dengan mudah } \\
\text { disesuaikan, } \\
\text { menggunakan tools } \\
\text { konvensional. }\end{array}$ \\
\hline \multirow[t]{2}{*}{ Keamanan } & $\begin{array}{l}\text { Adanya } \\
\text { rantai dan } \\
\text { sepeda. }\end{array}$ \\
\hline & $\begin{array}{l}\text { Adanya mekanisme } \\
\text { stopper pada stang. }\end{array}$ \\
\hline
\end{tabular}

Sumber: Mahendra, 2018

\section{Benchmarking Existing Product}

Dalam proses benchmarking, terdapat dua jenis existing product yang akan dijadikan sebagai tolak ukur. Dalam proses belajar sepeda terdapat 3 kemampuan yang perlu dilatih, yaitu balancing, pedaling, dan steering. Jenis existing product yang pertama adalah sepeda anak dengan tipe balance bike/push bike. Balance bike adalah jenis sepeda yang tidak memiliki pedal. Tujuan dari dihilangkannya pedal pada balance bike adalah supaya anak dapat dengan fokus mempelajari kemampuan balancing. Sedangkan jenis existing product yang kedua adalah sepeda anak konvensional. Untuk dapat melihat tolak ukur berdasarkan existing product yang ada, maka diambil beberapa adaptasi yang akan dipakai dalam desain sepeda baru.

1. Material frame

Secara umum dapat disimpulkan bahwa sepeda dengan frame berbahan alloy memiliki harga diatas Rp. 1.000.000,00. Untuk menekan biaya produksi, maka bahan steel dipilih sebagai bahan frame sepeda.

2. Ukuran ban

Pada existing product yang dibandingkan, terlihat bahwa pada sepeda dengan ukuran ban 12 inchi memiliki batas bawah umur pengguna 7 tahun, sehingga ban ukuran 12 diputuskan menjadi ukuran ban yang akan dipakai dalam desain sepeda baru.

3. Fitur tambahan

Untuk memberikan inovasi, maka diadaptasi sistem yang ada pada Miilo Bike dan Little Big Bike, yaitu sistem modular pada pedal, rantai dan gir depan yang dapat dilepas dari frame sepeda. Pada saat sepeda ada dalam mode balance bike, rongga pada frame bagian tengah cukup dalam, sehingga dapat juga digunakan untuk anak perempuan yang menggunakan rok.

\section{Menghasilkan Alternatif Desain}

Pendekatan yang digunakan pada setiap sketsa menggunakan adapt, combine dan modification dalam metode SCAMPER berdasarkan benchmarking yang telah dilakukan pada existing product. Gambar 1 menunjukkan 4 sketsa alternatif yang telah dihasilkan, beserta perubahannya dari mode balance bike dan mode sepeda berpedal. 


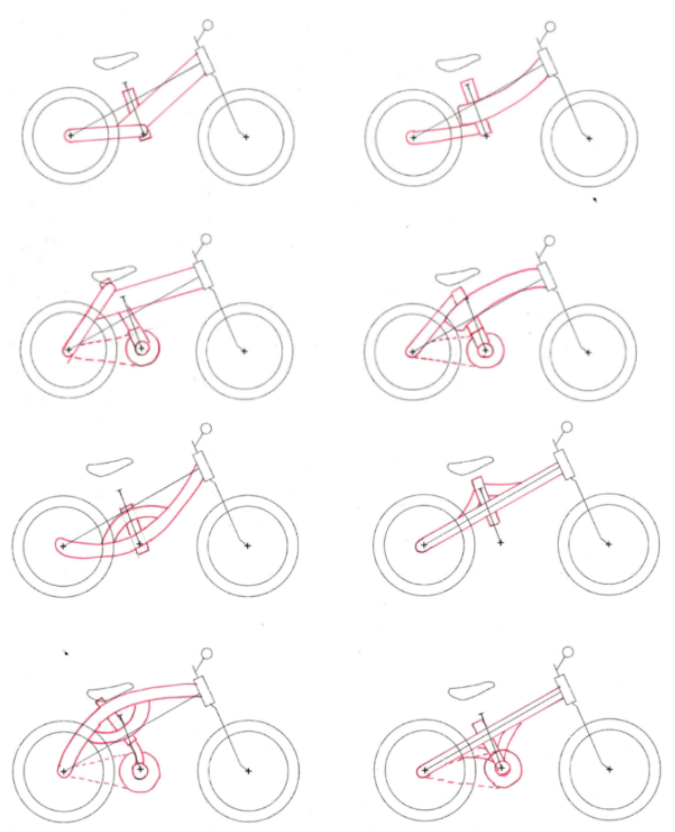

Gambar 1. Alternatif-alternatif sketsa Sumber: Mahendra, 2019

\section{Pemilihan Freeze Design}

Alternatif-alternatif desain yang telah dihasilkan kemudian ditunjukan kepada 6 orang anak dengan didampingi orang tuanya. Tahap ini dilakukan pada tanggal 14 Juli 2019. Proses pemilihan dilakukan oleh anak dan orang tua dengan ditunjukan hasil alternatif sketsa, kemudian diminta untuk menilai. Variabel penilaian yang digunakan adalah bentuk dan style. Skala yang digunakan untuk setiap variabel adalah skala Likert dengan bobot sangat puas (5), puas (4), cukup puas (3), kurang puas (2) dan sangat tidak puas (1). Berdasarkan hasil penilaian sketsa, maka terpilihlah sketsa nomor 3 .
Tabel 2. Rekap penilaian desain

\begin{tabular}{|l|r|r|r|}
\hline $\begin{array}{l}\text { Nomor } \\
\text { Sketsa }\end{array}$ & $\begin{array}{l}\text { Total } \\
\text { Nilai } \\
\text { dari } \\
\text { Bentuk }\end{array}$ & $\begin{array}{l}\text { Total } \\
\text { Nilai } \\
\text { dari } \\
\text { Style }\end{array}$ & $\begin{array}{l}\text { Total } \\
\text { Nilai }\end{array}$ \\
\hline Sketsa 1 & 27 & 21 & 48 \\
\hline Sketsa 2 & 21 & 19 & 40 \\
\hline Sketsa 3 & 25 & 24 & 49 \\
\hline Sketsa 4 & 26 & 22 & 48 \\
\hline
\end{tabular}

Sumber: Mahendra, 2019

\section{Pembuatan Hasil Akhir Desain}

Pada tahap pembuatan hasil akhir desain, desain yang terpilih diterjemahkan kedalam bentuk 3D menggunakan aplikasi Autodesk 3Ds Max.

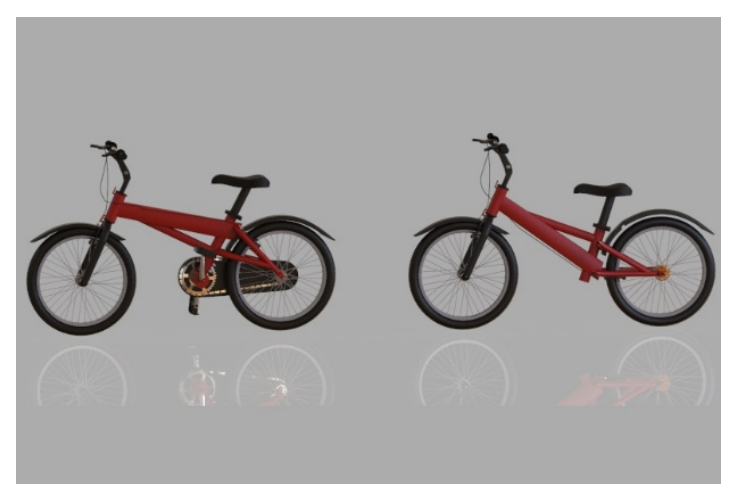

Gambar 2. Tampak samping desain baru Sumber: Mahendra, 2019

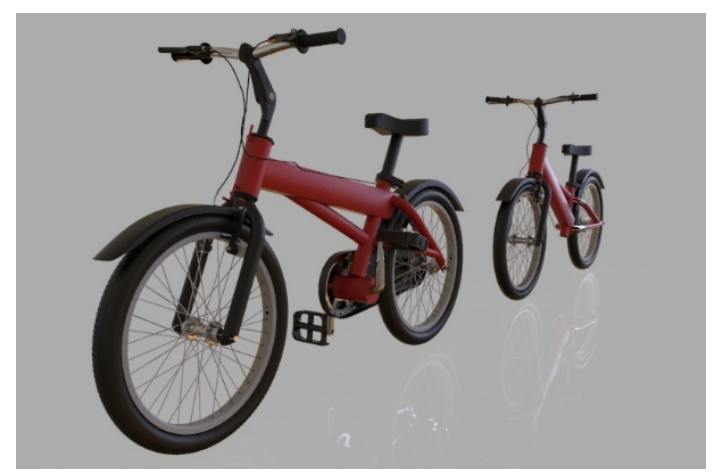

Gambar 3. Tampak perspektif desain baru Sumber: Mahendra, 2019 


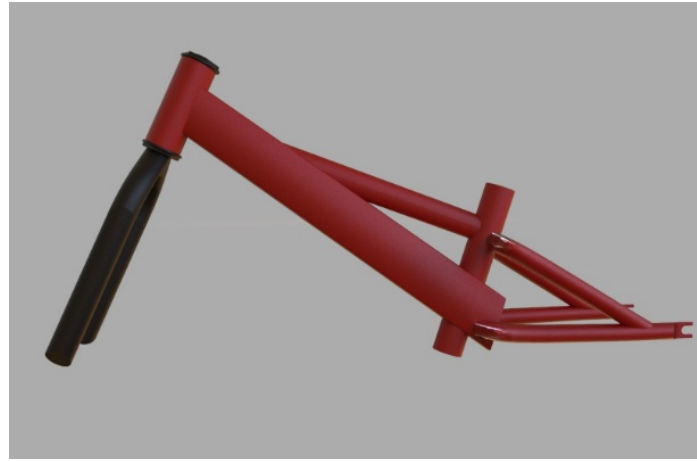

Gambar 3. Desain frame balance bike Sumber: Mahendra, 2019

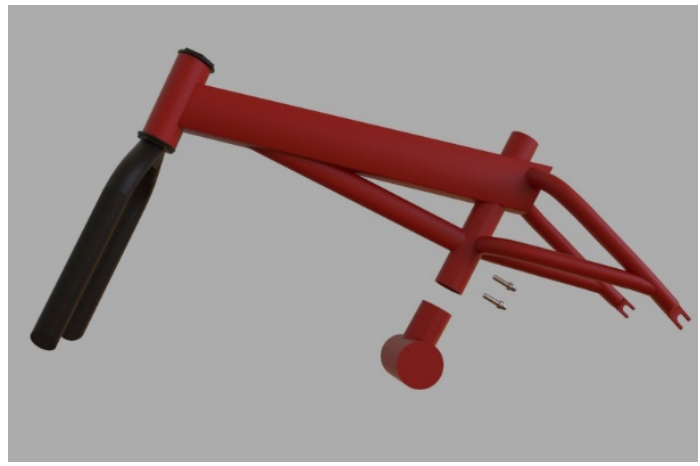

Gambar 4. Desain frame dengan modul pedal Sumber: Mahendra, 2019

Sepeda pada hasil akhir desain dapat digunakan untuk anak laki-laki dan perempuan, hal ini disesuaikan dengan antropometri anak laki-laki dan perempuan pada umur 7-12 tahun. Sepeda juga dapat digunakan dalam dua mode yaitu mode balance bike dan mode sepeda berpedal. Hal ini memberikan fleksibilitas penggunaan apabila anak sedang belajar bersepeda. Desain sepeda juga dapat digunakan dalam berbagai mode, seperti mode sepeda berpedal dengan model frame laki-laki, maupun perempuan dan mode sepeda nonpedal/balance bike dengan model frame laki-laki, maupun perempuan.

\section{Kesimpulan}

Berdasarkan penelitian yang telah dilakukan, maka dapat diambil kesimpulan sebagai berikut:

1. Desain sepeda yang sustainable akan mengurangi kebiasaan berganti-ganti sepeda pada anak seiring mereka bertumbuh.

2. Bagian pedal, gir depan dan rantai tergabung dalam satu modul yang dapat dilepas untuk mengakomodir mode belajar seperti pada balance bike.

\section{Daftar Pustaka}

Clark, G., Kosoris, J., Hong, L.N., Crul, M. (2009). Design for sustainability: Current trends in sustainable product design and development. Sustainability 2009, 1, 409-424. DOI: 10.3390/su1030409

Rodgers, P.A., Anusas, M. (2008, September 4 \& 5). Ethnography and design. International Conference on Engineering and Product design Education. https://www.academia.edu/1175 4717/Ethnography_and_Design

Serrat, O. (2009, February). The SCAMPER Technique. https://digitalcommons.ilr.corne 11.edu/cgi/viewcontent.cgi?articl $\mathrm{e}=1206 \&$ context $=$ intl 